\title{
TEOREMA DE PICK E O ESTUDO DE ÁREA E PERÍMETRO NO GEOPLANO ONLINE
}

\author{
Dafne Atz, PPGEMat/UFRGS - dafneatz@gmail.com
}

\begin{abstract}
Resumo: O estudo dos conceitos de área e perímetro pode gerar dúvida para os alunos do Ensino Fundamental. Com o intuito de esclarecer essas noções, buscou-se uma atividade que permitisse trabalhar com esses conceitos de uma maneira mais visual, possibilitando expandir, através do Teorema de Pick, a ideia de área dos polígonos trabalhados no $6^{\circ}$ ano do Ensino Fundamental de uma escola particular, a saber quadrados e retângulos e decomposições nestes polígonos. Foi utilizado para isso o Geoplano Online que proporcionou uma manipulação mais ágil de polígonos irregulares, onde os alunos enxergaram os conceitos envolvidos com mais facilidade, possibilitando a melhor compreensão dos mesmos. Sendo assim, este artigo busca trazer uma proposta de atividade investigativa elaborada para uma turma de $6^{\circ}$ ano, enunciando o Teorema de Pick, assim com algumas de suas aplicações.

Palavras-chaves: área e perímetro; ensino fundamental; teorema de Pick; investigação matemática; educação matemática.

\section{PICK THEOREM AND THE STUDY OF AREA AND PERIMETER USING AN ONLINE GEOBOARD}

Abstract: Studying concepts of area and perimeter can be somewhat difficult for middle school students. To seek a better way to clarify these ideas, we searched for an activity that would work with the concepts in a more dynamic and visual way. Pick Theorem made it possible to extent the study of area of squares and rectangles, and the decomposition into those polygons, to a deeper concept than is usually possible at a $6^{\text {th }}$ grade level of a private school. An online Geoboard made it feasible through facilitating fast manipulation of irregular polygons, where students could easily works with de concepts, understanding it better. This paper proposes an investigative activity designed for students at a $6^{\text {th }}$ grade level where we will be enunciating the Pick Theorem, and some of its applications.

Keyword: area and perimeter; middle school; Pick theorem, math investigation; math education.

\section{Introdução}

Para muitos alunos os conceitos de área e perímetro podem ser nebulosos. Quando solicitados a contar a área em uma figura representada na malha quadriculada a grande maioria conta cada quadrado que representa a unidade. O mesmo acontece com o perímetro, onde os alunos contam cada "lado", sem somar ou multiplicar todas as medidas. Isso quando sabem o que cada conceito representa, sem confundi-los.

Baltar (1996), ao estudar a aquisição da relação entre comprimento e área na escola, relata as dificuldades que estudantes dos anos finais da educação básica encontram, em primeiro lugar, em reconhecer medidas de uma figura como um de seus elementos constituintes e, em segundo, em distinguir as medidas de área e de perímetro. Em tal pesquisa, foi evidenciado o fato de que os aspectos da aprendizagem de diferentes elementos de medida (de comprimento, de área, etc.) são específicos e diversos entre si; assim, a ideia de área de uma figura plana não é sempre reconhecida como uma característica de tal figura. (HENRIQUES, 2011, p. 28) 
Com o objetivo de esclarecer tais conceitos aos alunos, a ideia era elaborar uma proposta que permitisse aos educandos perceber que área e perímetro são duas grandezas diferentes, e que mesma área não significa mesmo perímetro e vice-versa. Os alunos já estavam familiarizados com a ideia de divisores de um número, e como representar quadrados e retângulos na malha quadriculada, pois já haviam realizado trabalho utilizando este material (ATZ, 2015). A partir disso, buscou-se recurso digital que mantivesse a proposta do trabalho anterior, de construção e análise do que os alunos produziam, fazendo-os refletir e, através do diálogo entre a turma, alcançar os objetivos esperados. Para tanto, foi escolhido o Teorema de Pick.

A partir do teorema, surgiu a proposta de trabalhar em duplas e analisar a noção de área em situações aplicadas, em um ambiente mais dinâmico que possibilitasse a investigação por parte dos alunos. Como ressalta Jardim; Portanova (2010) e Megid (2010), sabemos que trabalhos em duplas e grupos permitem que o aluno se sinta mais confortável a compartilhar suas ideias e percepções, gerando discussões que enriquecem o aprendizado.

Além disso, se temos um recurso diferente, que permita uma manipulação e construção mais ágil e eficaz do proposto, podemos ter uma atividade mais atraente para o aluno, pois "se para ensinar geometria, um dos problemas enfrentados é a falta de observação, manipulação e visualização de objetos geométricos como observa Kaleff (1998), a informática pode ser uma grande aliada a esses aspectos" (BALDINI, 2004, p. 28).

A seguir será enunciado o Teorema de Pick e a metodologia e proposta utilizada para a elaboração e aplicação das atividades com a turma. São expostas algumas situações e discussões geradas pelos alunos que surgiram no decorrer da aula, assim como alguns trabalhos feitos pelos educandos e suas conjecturas e conclusões.

\section{O Teorema de Pick}

Georg Alexander Pick é judeu nascido em Viena no ano do 1859. Trabalhou em diversos campos da matemática, porém sua maior contribuição foi o Teorema de Pick, publicado em seu artigo Geometrisches zur Zahlenlehre, em Praga em 1900. Entretanto, este resultado só se tornou conhecido e admirado em 1969, quando o matemático $\mathrm{H}$. Steinhaus o incluiu em um de seus trabalhos.

O teorema traz que:

"A área de um polígono simples representado em uma malha quadriculada é dada por

$$
A=I+\frac{B}{2}-1
$$

onde I é a quantidade de pontos interiores do polígono e B é a quantidade de pontos da borda do polígono".

Algumas definições precisam ser ressaltadas para que se compreenda o teorema: $\rightarrow$ Polígono simples: é um polígono formado por segmentos de reta que não se cruzam.

$\rightarrow$ Pontos interiores (I): são os pontos da malha quadriculada que fazem parte do interior do polígono.

$\rightarrow$ Pontos da borda (B): são os pontos que se encontram em cima dos lados (segmentos de reta) do polígono.

Veja o exemplo a seguir: 


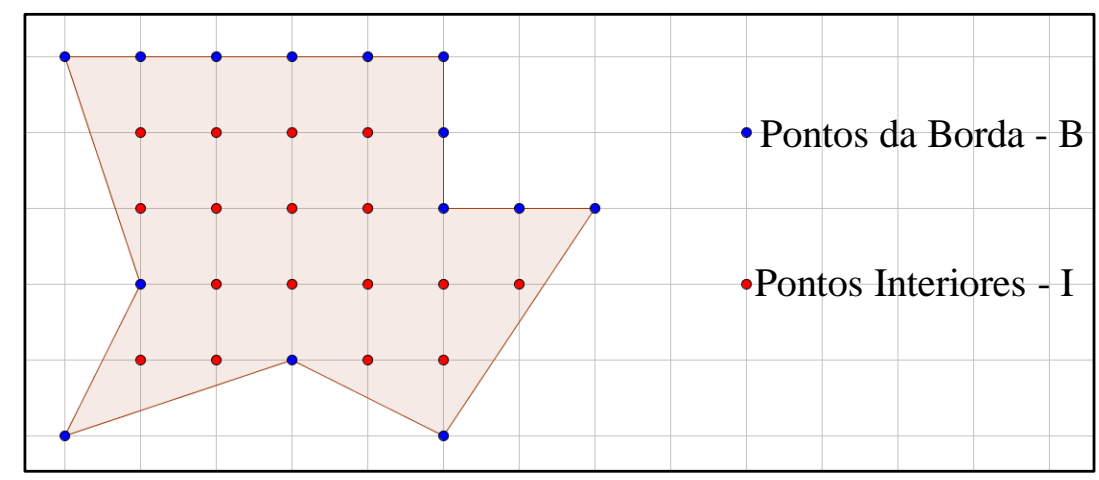

Figura 1 - Octógono Irregular

Na figura 1, o octógono apresenta 14 pontos na borda e 17 pontos interiores; aplicando o Teorema de Pick temos:

$$
A=17+\frac{14}{2}-1=17+7-1=23 \text { u.a. }
$$

\section{Metodologia e proposta}

O plano, elaborado para uma turma de 35 alunos de uma escola particular do município de Portão, que tinha por objetivo utilizar a decomposição em quadrados e retângulos para determinar a área de polígonos, e posteriormente concluir a fórmula do Teorema de Pick. As aulas foram realizadas no laboratório de informática, onde os alunos se dispuseram em duplas e um trio, com acesso ao Geoplano Online (http://escolovar.org/mat_geometri_geoplano.mathplay.swf), onde foram utilizados 4 períodos de 50 minutos cada, para trabalhar com os alunos os conceitos de área e perímetro, assim como o Teorema de Pick.

\subsection{Desenvolvimento da proposta}

Em um primeiro momento foi questionado aos alunos quem lembrava o que era área e perímetro; e como era de se esperar, vários fizeram o comum erro de trocar os conceitos, mas se questionando se estavam certos! Estes conceitos já haviam sido comentados em aulas anteriores, quando trabalhada a multiplicação de frações. Nos dirigimos então ao laboratório de informática onde os computadores já estavam ligados e com o programa aberto. Assim que os alunos se acomodaram em duplas à frente dos computadores, com o auxílio de um projetor, foi explicado o básico do aplicativo do Geoplano Online (que será referido apenas como Geoplano), ver figura 2.

Ponte (2005) ressalta como a fase inicial do processo de investigação é importante para que o aluno compreenda o que está por vir. Com este intuito, foi explicado como inserir o elástico, como movimentá-lo, as posições que ele pode assumir, assim como as opções de cores de preenchimento, para que os alunos compreendessem o aplicativo que usaríamos em aula, auxiliando-os a analisar e interpretar as situações propostas. Não foi dado ênfase, porém, para o botão "Measure" que calcula a área e o perímetro da figura selecionada, pois o objetivo era que os alunos trabalhassem um momento sem o auxílio desta ferramenta e possivelmente descobrissem sozinhos como ela funcionava.

Após também relembrarmos o que era um polígono (figura plana formada por segmentos de reta simples), ficou combinado com os alunos que a distância entre cada ponto do Geoplano seria u.c., enquanto a área seria representada como u.a. . Foi então solicitado que os alunos representassem três polígonos que tivessem 9 u.a., e esses 
polígonos poderiam ter o formato que eles quisessem. Muitos alunos se prenderam a quadrados e retângulos, poucas duplas pensaram em figuras diferentes.

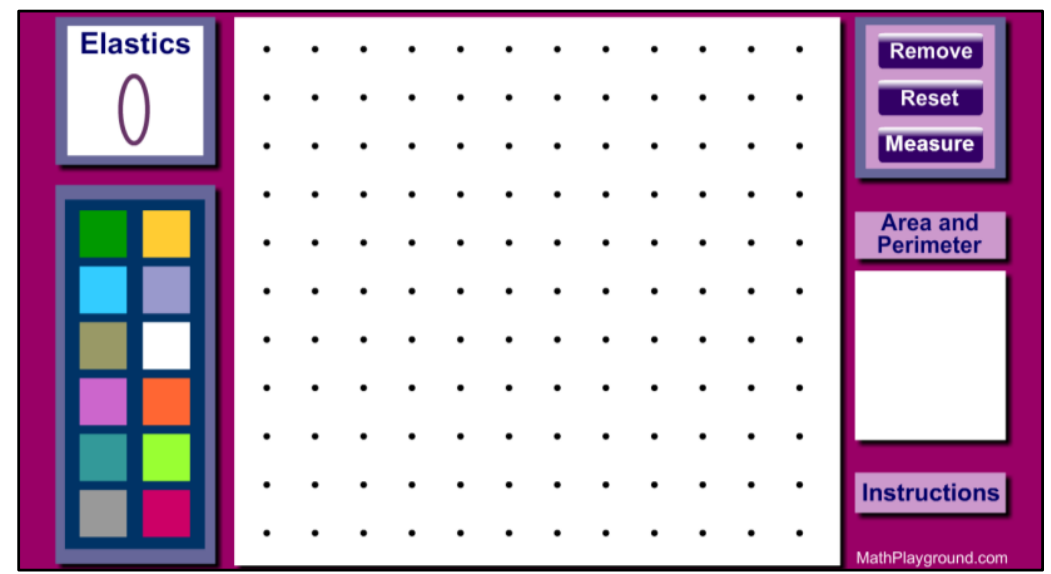

Figura 2 - Geoplano Online

Foram selecionados polígonos de algumas duplas que já haviam terminado e construída uma tabela com a área e o perímetro de cada um deles, conforme podemos ver na figura 3. Nos cinco primeiros desenhos os alunos conseguiram calcular facilmente a área e o perímetro, já no polígono $\mathrm{F}$, eles questionaram mais, e alguns alunos analisaram dividindo o polígono em partes, percebendo que a cada dois meios triângulos tínhamos 1u.a., o que possibilitou o cálculo. Quando questionei os alunos com relação ao perímetro, as respostas se dividiram em 14, 15 ou 16 unidades de comprimento. Neste momento, com o auxílio de uma régua não graduada, comparamos a medida da lateral de um quadrado com a de sua diagonal, vendo assim que não representavam o mesmo valor. Deixamos então a análise do perímetro do polígono F para outro momento.

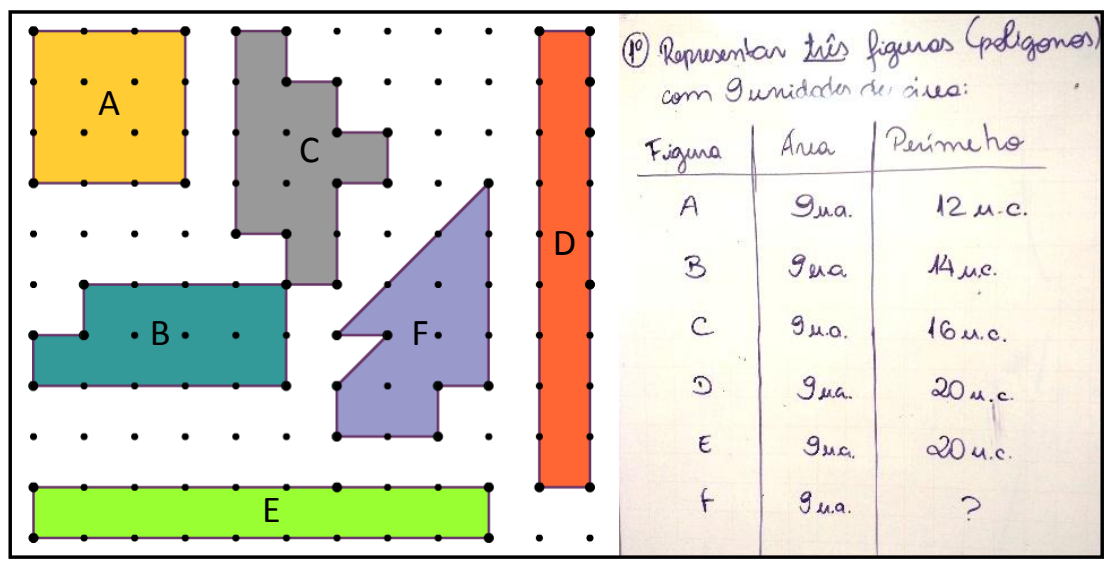

Figura 3 - Construções de polígonos com 9 u.a. feitas pelos alunos e tabela com áreas e perímetros

Já nesta primeira situação os alunos não pareceram surpresos com o fato de termos perímetros diferentes para polígonos com mesma área, quando questionados o porquê isso acontecia, ouviu-se a mesma resposta de vários: "pois são figuras diferentes!", ou ainda, "pois mesmo com a mesma área, os polígonos não tem o mesmo formato!".

A nova tarefa consistia em criar quatro polígonos que tivessem 12 unidades de área. Circulando entre os alunos percebeu-se que uma das duplas havia descoberto a ferramenta Measure, e outra aluna havia questionado para que o espaço branco abaixo de Area and Perimeter servia. Chegamos aqui ao ponto onde a curiosidade dos alunos os levou naturalmente a fazer novas descobertas, aspecto procurado no trabalho. 
$\mathrm{Na}$ figura 4 vemos algumas das construções dos alunos para os polígonos de 12 unidades de área. Muitas duplas ainda se prenderam aos quadrados e retângulos, porém quando descobriram a ferramenta Measure rapidamente começaram a criar polígonos diferentes e ficaram ansiosos por compartilhar seu trabalho com os colegas. Esta liberdade em compartilhar o que eles descobriram reforça o que Megid (2010, p.187) traz em um de seus textos: "Quando se abre a possibilidade de discussão, os alunos se empolgam e a aprendizagem torna-se significativa.".

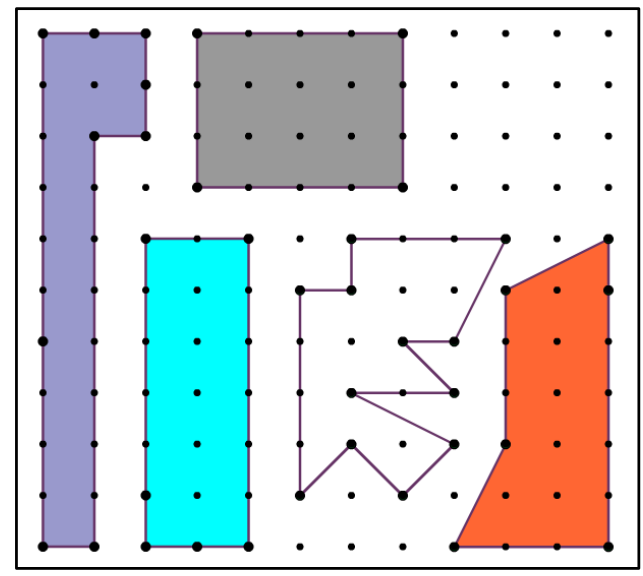

Figura 4 - Construções de polígonos com 12 u.a. feitas pelos alunos

No plano inicialmente elaborado estavam previstas outras construções guiadas, solicitando aos alunos figuras com determinada área ou perímetro, para que pudéssemos analisar semelhanças e diferenças, porém como rapidamente compreenderam os conceitos e a ideia do trabalho, foi antecipado o momento onde eles estariam livres para criar polígonos "malucos".

Agora, já acostumados com o Geoplano e sabendo seu funcionamento, a atividade proposta para a turma consistia em criar 10 polígonos malucos, registrando em uma tabela a quantidade de pontos da borda da figura, os pontos interiores, a área e o perímetro. Além disso, cada polígono criado deveria ser salvo, em um documento de texto, identificando qual o número da imagem correspondente aos valores registados. Novamente foram necessárias algumas combinações, onde ficou definido que pontos da borda eram todos os pontos pelos quais os lados do polígono passavam e pontos interiores eram os pontos dentro do polígono (conforme enuncia o Teorema de Pick). Valores de área e perímetro deveriam ser anotados do próprio Geoplano. Devido ao tempo, foi necessário interromper a atividade no final de dois períodos, para que pudéssemos continuar no dia seguinte.

Retomando a atividade no outro dia, os alunos tiveram tempo de finalizar as construções dos polígonos malucos assim como os registros na tabela entregue no dia anterior. Enquanto eles finalizavam, circulando entre os alunos, percebeu-se, através dos registros na tabela, que uma das duplas havia construído diversos polígonos onde haviam zero pontos interiores. Antes que todos terminassem seus trabalhos, foram selecionadas algumas das construções que já estavam prontas do dia anterior, cuidando para selecionar uma de cada dupla.

Foi solicitado então que os alunos deveriam analisar os valores registrados nas tabelas, buscando algum padrão, algo que acontecia sempre na hora de calcular a área! Como vemos em Polya (1995), quando ele trabalha a resolução de problemas, "O professor deve auxiliar, nem demais nem de menos, mas de tal modo que ao estudante caiba uma parcela razoável do trabalho". Devido ao olhar confuso de alguns, ressaltou-se que havia "uma conta, envolvendo adição, subtração, multiplicação e/ou divisão, que 
sendo realizada com os pontos da borda e com os pontos interiores resulta na área registrada na tabela. Que conta será essa?".

Devido à complexidade e ao tempo curto que tínhamos, acreditava-se que eles não conseguiriam concluir o teorema em tempo de discuti-lo, porém, após 10 minutos uma das duplas (a que havia registrado vários polígonos com zero pontos interiores) disse que talvez tivesse chego a uma conclusão!

Professora: O que encontraste?

Aluno M: Eu dividi o número da borda por dois, somei o do interior e tirei um! Mas não tenho muita certeza...

Professora: Já fizeste a conferência para todos?

Aluno M: Ainda não! Por isso estou na dúvida! Tem alguns que não deram muito certo, mas eu vi que um eu anotei errado!

O trabalho destes dois alunos aparece na figura 5 e na figura 6 , onde podemos ver os diversos pontos interiores zero, juntamente de seus polígonos que o auxiliou a concluir o teorema.

\begin{tabular}{|c|c|c|c|c|}
\hline Figura & Pontos da borda & Pontos interiores & Area & Perimetro \\
\hline$n .1$ & 27 & 78 & $88.5 \mathrm{co}$ & 45.24 \\
\hline n. 2 & 7 & 4 & $6.5 \mathrm{sa}$ & 12. 09 \\
\hline n.3 & 9 & 0 & $3.5 \mathrm{sg}$ & 14.5 \\
\hline n. 4 & 8 & 13 & $16 \mathrm{sa}$ & 38.53 \\
\hline n. .5 & 4 & 0 & $1 \mathrm{sa}$ & 4 \\
\hline n. 6 & 22 & 0 & $10 \mathrm{sa}$ & 20.28 \\
\hline$n .7$ & 29 & 0 & $14 \mathrm{Sa}$. & 44.87 \\
\hline$n .8$ & 22 & 0 & $10 \mathrm{so}$ & 22 \\
\hline n.9 & 4 & 1 & $2 \mathrm{sa}$ & 9.6 \\
\hline n.10 & 4 & 16 & 17 & 29.09 \\
\hline
\end{tabular}

Figura 5 - Tabela da dupla dos alunos M e G

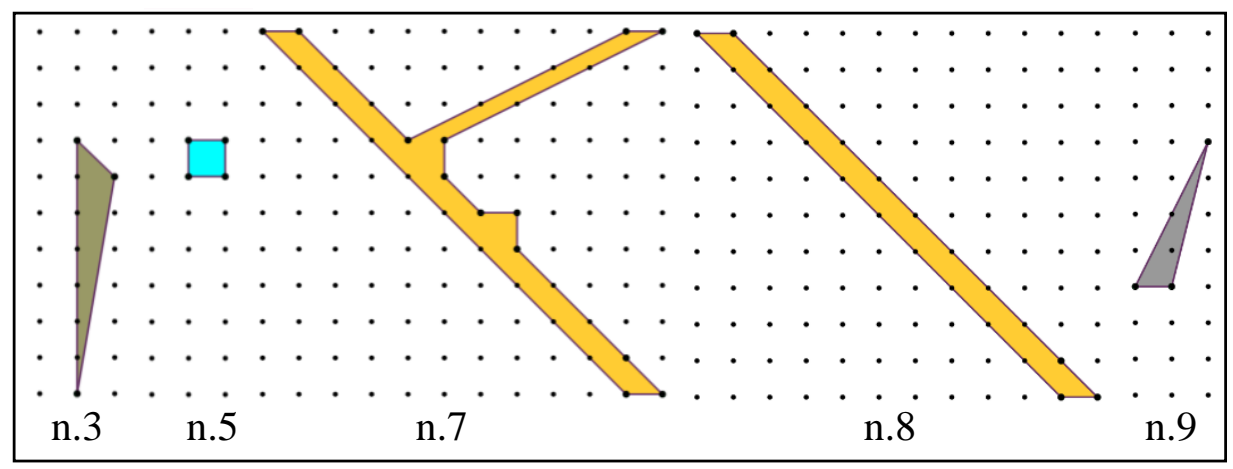

Figura 6 - Algumas das construções da dupla dos alunos M e G

Estimulado a conferir e rever os valores anotados o aluno retornou após alguns minutos dizendo que era isso mesmo! Neste momento socializamos com a turma a sua descoberta e anotamos de forma simples no quadro:

pontos da borda $\div 2+$ pontos interiores $-\quad 1 \stackrel{?}{=}$ Área 
E iniciamos a conferência para os polígonos já selecionados. Os primeiros analisados foram retângulos e polígonos onde fosse mais fácil a conferência, partindo para outros onde os alunos deveriam pensar em metade de triângulos, para após algumas constatações, verificar que aquela sentença matemática realmente funcionava para vários polígonos mais complexos (também criados pelos alunos, conforme exemplo na figura 7).

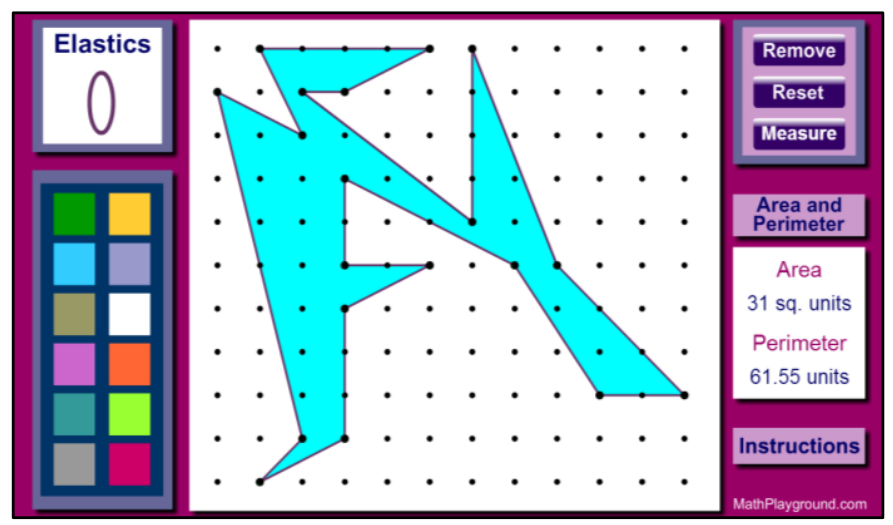

Figura 7 - Polígono criado pelos alunos

Após calcularmos a área da figura 7, uma aluna, que havia chegado atrasada e pegou o trabalho em andamento, questionou o que aconteceria se o número de pontos da borda fosse ímpar, uma vez que dividimos este valor por 2 , e ela completou a própria pergunta dizendo "Fica com vírgula?". Ainda não foi dado ênfase neste ano aos números decimais, porém os alunos já possuem o conhecimento necessário para analisar situações simples onde precisamos dividir por 2, pois ao fazer comparações com seu cotidiano, onde o contato com dinheiro é diário, percebe-se que seu raciocínio acontece com mais facilidade, que é o que Megid (2010) também nos traz, ao relatar que a partir do que os alunos já conhecem, podemos fazer conexões que os auxiliem a refletir sobre o novo, promovendo o diálogo entre eles. Com isso, foi feita uma rápida conversa com a turma de situações simples onde temos que dividir determinada quantia entre duas pessoas, remetendo então essa ideia para o exemplo do polígono representado na figura 8 .

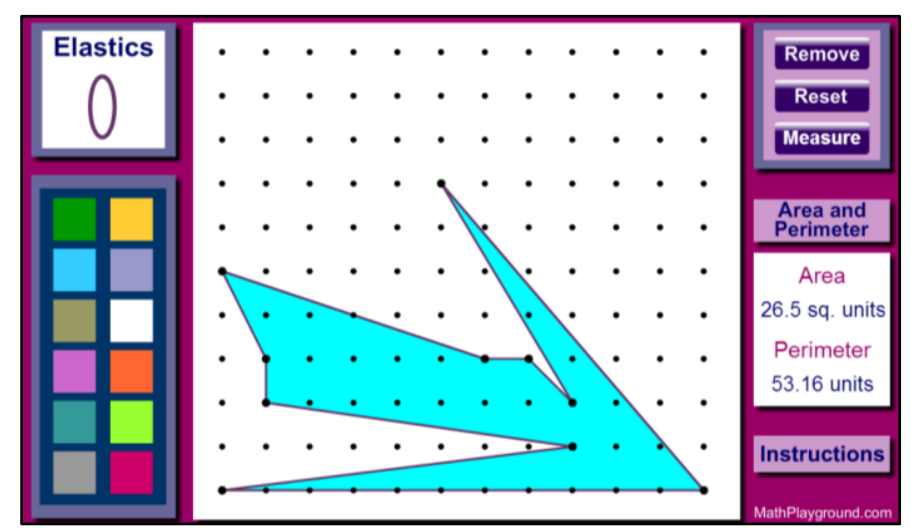

Figura 8 - Polígono com número ímpar de pontos interiores

Após conferirmos o cálculo sugerido pelo aluno $\mathrm{M}$ neste último polígono, foi enunciado para os alunos a fórmula do Teorema de $\mathrm{Pick}^{1}$, ressaltando que é utilizada para calcular a área de polígonos em cima de um plano que relembra uma malha quadriculada. Reforçamos ainda o que o $I$ e o $B$ significam; conferindo então algumas das outras

${ }^{1} A=I+\frac{B}{2}-1$, onde $B$ é o número de pontos da borda e $I$ é o número de pontos interiores. 
construções dos alunos no Geoplano. Além disso, foi conversado com a turma um pouco da história de Georg Alexander Pick e como o teorema é utilizado atualmente.

Conversamos que na medicina ele e utilizado para analisar áreas de pele machucadas ou comprometidas de alguma forma; que na geografia não podemos medir com precisão a área de estados, cidades e regiões de terra e para ilustrar uma situação foi desenhada uma "ameba" no quadro, sob a projeção do Geoplano (figura 9). Foi questionado aos alunos se teríamos como calcular aquela área, ao que eles responderam que não. Então desenhamos um polígono que se aproximasse da ameba, ligando pontos próximos no Geoplano, alguns deixando a ameba menor, outros maior, para que pudéssemos ter uma aproximação. Após construirmos este polígono aproximado, calculamos a área com o auxílio do aplicativo.

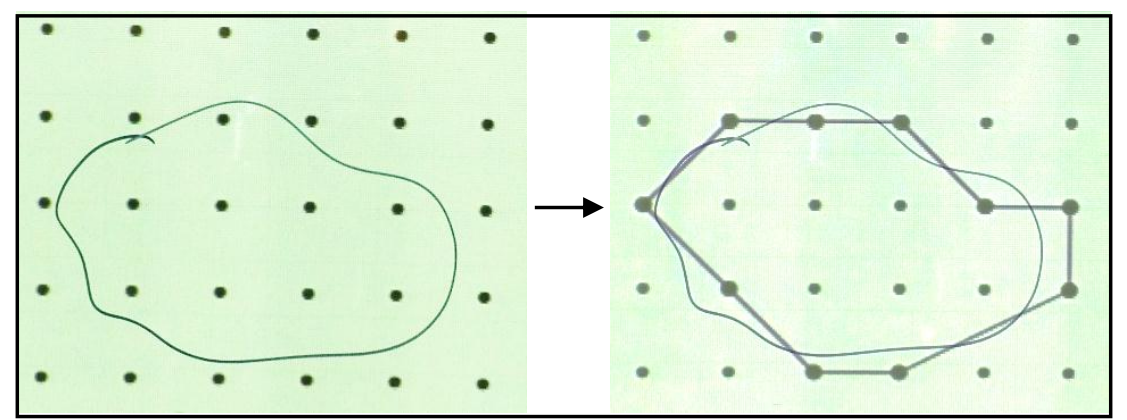

Figura 9 - "ameba" representada no quadro sob o Geoplano e o polígono aproximado

Quando questionados onde mais eles consideram útil a utilização do teorema, um dos alunos comentou que caso quiséssemos fazer um lago ele também seria válido, pois nos permitiria, através da visão aérea aproximar a área desejada. Outro questionamento que surgiu por parte dos alunos foi com relação ao perímetro e se haveria algum teorema parecido para o cálculo deste.

Como estava chegando próximo do final dos dois períodos (pois 20 minutos de um deles havia sido destinado ao projeto leitura na escola, onde todas as turmas param e leem por 15 minutos) os alunos foram solicitados a salvar seus trabalhos e guardar seus materiais.

\section{Considerações Finais}

Uma investigação, de acordo com Ponte (2005), possui alguns momentos específicos. Ele enfatiza que há um primeiro momento de exploração e formulação de questões, outro de conjecturas, um de testes e o final onde justificamos e avaliamos os resultados encontrados. Nessa perspectiva, vemos que os alunos tiveram o momento de explorar o programa e as situações propostas, organizar os dados nas tabelas, analisar e fazer conjecturas de possíveis fórmulas e maneiras para calcular a área testando-as e analisando a veracidade do que lhes era proposto. Devido à complexidade de uma justificativa para o teorema, este momento fortemente matemático não ocorreu, mas isso não impediu os alunos de perceberem que o resultado era válido e avaliar o raciocínio utilizado, conforme vemos no trabalho de uma das duplas (Figura 10).

Apesar de apenas uma das duplas ter encontrado a fórmula do Teorema de Pick, e outra ter chego próximo ao resultado, o compartilhamento realizado com a turma fez com que todos compreendessem a equação proposta pelos colegas e os alunos prontamente testaram em suas anotações. 


\begin{tabular}{|c|c|c|c|c|}
\hline Figura & Pontos da borda & Pontos interiores & Area & Perímetro \\
\hline n.1 & $12 \div 2=6$ & $-13=19$ & 18 & 21.1 \\
\hline n.2 & $12 \div 2=6$ & $-g=15-1 z$ & $14^{\circ}$ & 17.88 \\
\hline n.3 & $15 \div 2=75$ & $26 \quad 3,5,-1$ & 32.5 & 34.02 \\
\hline n.4 & $14: 2=7<$ & $4=11-1=$ & 10 & $A, 3$ \\
\hline n.5 & $12: 265$ & $+13=19,5$ & $=18.5$ & 30,23 \\
\hline n.6 & $g=2-45$ & $+3=754$ & 6.5 & 157 \\
\hline n.7 & $282=19$ & $+0=19-1=$ & 18 & 3883 \\
\hline n. 8 & $4=2=2$ & $r \quad 12=14$ & $1=13$ & 14.42 \\
\hline n.9 & $7 \geq 2=35$ & $+2=55-1$ & 4,5 & 9.16 \\
\hline n.10 & $4 \times 2=$ & $+7-911$ & 8 & 12.65 \\
\hline
\end{tabular}

Figura 10 - alunos testando e avaliando os valores encontrados através do Teorema de Pick

$\mathrm{Na}$ proposta de uma atividade de investigação matemática, percebe-se que os alunos interagem mais e participam com mais entusiasmo das aulas. $\mathrm{O}$ auxílio do recurso digital os estimula a querer aprender. No início da primeira aula, apesar de o aplicativo já estar aberto na tela, foi possível ver uma dupla chegando no laboratório de informática e buscando sites de jogos.

$\mathrm{O}$ uso que nossos alunos veem atualmente para um computador com acesso à internet tem se resumido a jogos online e brincadeiras. Mas porque não trazer essa vontade de brincar para um aplicativo que possibilite, além do divertimento, o aprendizado de algo novo?

Sabemos que alguns de nossos alunos são mais rápidos do que outros ao realizar atividades, e muitas vezes precisamos de material extra para que ele não se sinta entediado! No desenvolver desta atividade, após a turma perceber as potencialidades do aplicativo Geoplano Online, foi possível visualizar vários alunos, dos quais já haviam terminado o trabalho, criando casas, cadeiras, objetos diversos com o uso do aplicativo, explorando suas cores e formas (Figura 11).

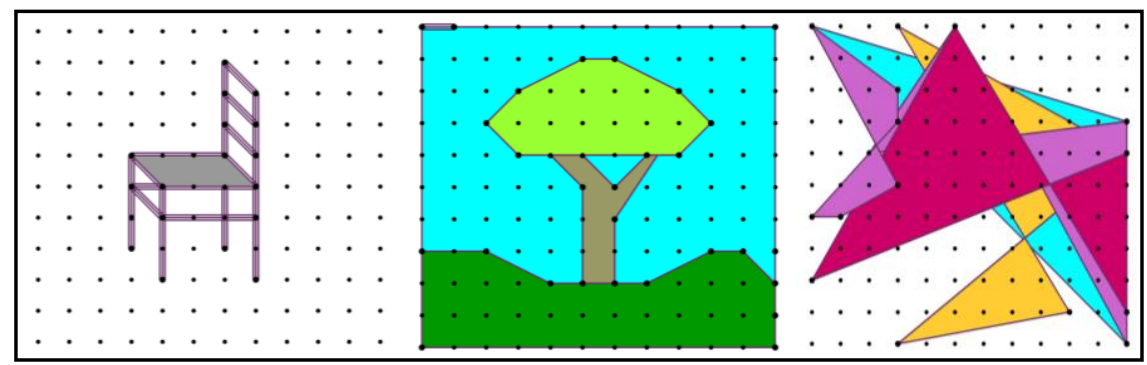

Figura 11 - criação dos alunos no Geoplano Online

Analisando a atividade investigativa, percebe-se que os compartilhamentos que a turma fazia possibilitavam um andamento mais eficaz a aula, uma compreensão maior do proposto e um engajamento diferente daquele que vemos em sala durante uma aula onde os alunos devem trabalhar individualmente. Percebe-se que ao final da atividade, a maioria dos alunos demonstrou ter compreendido de forma mais clara o que a área representa, apropriando-se do conceito, e, dessa forma, esclarecendo também o conceito de perímetro.

Devemos buscar sempre em nossos alunos o prazer em aprender, mostrando que a matemática pode ser divertida. Além disso, como professores, precisamos nos sentir à 
vontade para utilizar recursos digitais. O medo que muitos possuem de correr o risco de algum questionamento inusitado, muitas vezes nos impede de momentos de grande aprendizado para o aluno. Precisamos arriscar mais e ousar mais em nossas aulas, saindo do quadro e partindo para recursos mais atrativos aos nossos educandos.

\section{Referências Bibliográficas}

ATZ, Dafne. Utilizando a Representação Geométrica no Estudo de Divisores de um Número Natural no $6^{\circ}$ Ano do Ensino Fundamental. In: Anais do XII EGEM Encontro Gaúcho de Educação Matemática, Instituto de Matemática da Pontifícia Universidade Católica do Rio Grande do Sul. Porto Alegre: PUC, 2015.

BALDINI, L. A. F. Construção do Conceito de Área e Perímetro: Uma Sequência Didática com Auxílio de Software de Geometria Dinâmica, no Estado do Paraná. Londrina: Universidade Estadual de Londrina, 2004. 211p. Dissertação de Mestrado.

GEOPLANO ONLINE. Disponível em:

$<$ http://escolovar.org/mat_geometri_geoplano.mathplay.swf $>$ Último acesso em $19 / 10 / 2015$.

HENRIQUES, M. D. Um Estudo Sobre a Produção de Significados de Estudantes do Ensino Fundamental para Área e Perímetro, no Estado de Minas Gerais. Juiz de Fora: Universidade Federal de Juiz de Fora, 2011. 219p. Dissertação de Mestrado.

JARDIM, Rosane Lopes; PORTANOVA, Ruth. Aprendendo geometricamente: divisores, números primos e compostos, maior divisor comum, múltiplos e menor múltiplo comum de um número natural. Acta Scientiae, v.12, n.1, p.95-111, jan/jun. 2010.

MEGID, Dora. Construindo matemática na sala de aula: uma experiência com os números relativos. In: FIORENTINI, Dario (org.). Por trás da porta, que matemática acontece? Campinas: Editora Ilion, 2010.

POLYA, G. A Arte de Resolver Problemas: Um Novo Aspecto do Método Matemático. Rio de Janeiro: Editora Interciência, 1995.

PONTE, João Pedro da, BROCARDO, Joana, OLIVEIRA. Investigações matemáticas na sala de aula. Belo Horizonte: Editora Autêntica, 2005.

RODRIGUES, I. M. Área de Figuras Planas e Teorema de Pick: Uma Abordagem Diferenciada para Alunos do $6^{\circ}$ Ano do Ensino Fundamental, no Estado do Amazonas. Manaus: 2014. 61p. Dissertação de Mestrado. 